Received: November 11, 2017

Revision received: May 21, 2018

\title{
Research on Application of Collaboration Ability in Kindergarten Game-based Education
}

\author{
$\mathrm{Na} \mathrm{Yao}{ }^{1}$ \\ Tangshan Normal University
}

\begin{abstract}
In the cultivation of the children's cognition for the society and culture, the game-based education in the kindergarten is an important way to develop their collaboration abilities in the games and greatly enhance children's self-confidence and imagination. In this paper, the application of collaboration in kindergarten gamebased education was studied under the background of kindergarten multicultural education. The results have shown that children can learn about the diverse cultures through cultural game-based education, and greatly enhance their collaboration abilities as a team member in the games. The collaboration cultivated in the gamebased education is closely related to the curriculum content and the teacher's professionalism. The frequency of teaching cases varies with game behaviors, in which construction games see the most teaching cases. This paper can serve as a theoretical reference for researches on the application of collaboration ability in children's game-based education.
\end{abstract}

\section{Keywords}

Kindergarten • Game-based Education • Multicultural Education • Collaboration

\footnotetext{
"Social science fund project of Hebei province; Study on the gamification model of construction activity curricula in kindergartens; HB18JY054

${ }^{1}$ Correspondence to: Na Yao (MA), Tangshan Normal University, Tangshan 063000, China. Email: 13932582036@163.com
}

Citation: Yao, N. (2018). Research on Application of Collaboration Ability in Kindergarten Game-based Education. Educational Sciences: Theory \& Practice, 18(5), 2470-2477. http://dx.doi.org/10.12738/estp.2018.5.147 
Preschool education is vital for children to develop their sociality and personality, and to cultivate their cognition, language and intelligence at the fastest speed (Coughlin, 2015). Preschool children living in a multicultural society cannot avoid various multi-culture-induced problems. Therefore, collaborative multicultural education for preschool children can help them form attitudes and strategies to adapt to a multicultural society, and also lay a foundation for children's social adaptability in the future (Lee, 2013). Studies have shown that kindergarten game-based education can lay the foundation for children to establish a concept of solidarity and cooperation, and facilitate them to be responsible citizens in a multi-cultural society (O'Malley, 2017). Kindergarten game-based education is an important way of multicultural education practice. Children with low understanding ability can learn about more cultures through games. Thus, the kindergarten can regard game-based education as an important way of multicultural education (Green, 2013).

According to the different division of labour in the team, behavioural research can be divided into three modes: cooperation, support, and independence. The complete preschool education should involve content integration, knowledge establishment, equal teaching, prejudice reduction, and school culture enhancement (Barnett, 2015, Silverman, Hong \& Trepanierstreet, 2010). To achieve preschool education in a multi-cultural environment, the game-based education is the fastest way for children to understand things, in which children can understand the role of collaboration in games (Yilmaz \& Chb, 2016). Grouping practices are the foundation of collaboration, and students in a collaborative learning environment can better acquire social skills and more easily adapt to the multicultural society in the future (Lazzari, 2012). This paper studied the application of collaboration in kindergarten game-based education under the background of kindergarten multicultural education.

\title{
Categories and Connotations of Kindergarten Game-based Education
}

The relationship between games and kindergarten curriculums and teaching has always enjoyed attention and debates from scholars during the reform and development of preschool education in China (Cicconi, 2014). Games are based on the interests of children and involve potential and possible educational elements in the multicultural education, in which children can express and demonstrate themselves by using their existing experience (Eckhoff, 2011). Kindergarten game-based education includes free games, guided games, and direct teaching games, which is a multi-element teaching method in pre-school education. Guided games are games that are initiated with set goals by teachers to encourage children's self-exploration and discovery, in which children are planned to learn as the subject. Free games and direct teaching games are the two extremes of kindergarten game-based education, both of which impose little effect on the multicultural education. In kindergarten game-based education, teachers should observe and analyze the game behaviors of children to develop corresponding game rules so as to help children gain more experience in games.

\section{Ongoing Actions for Kindergarten Game-based Multicultural Education}

\author{
Analysis of the Status Quo of Kindergarten Game-based Multicultural Education
}


As an important way of kindergarten education, games should be more integrated with the multi-culture. In order to understand the current situation of game-based multicultural education in kindergartens in Guangdong Province, 30 kindergartens were randomly selected for evaluation. Figure 1 shows the mean of kindergarten interaction scores. It can be seen that the scores of indoor general activities, outdoor sports activities and teacherchild interaction are higher. Comprehensively, there is a lack of multi-cultural games and teachers have insufficient knowledge of game-based multicultural education. Figure 2 shows the mean of multi-culture and difference acceptance. It can be seen that teachers' multicultural literacy and respect and appreciation for differences have met the eligibility criteria. In the teacher-child interaction, teachers should pass on different cultures through diversified games, which requires teachers to understand and have the ability to spread multicultures. For different grades, the kindergarten's game-based multicultural education activities should be advanced from no structure, simple structure, advanced structure to complete structure, emphasizing the value of game-based education activities in multicultural communication.

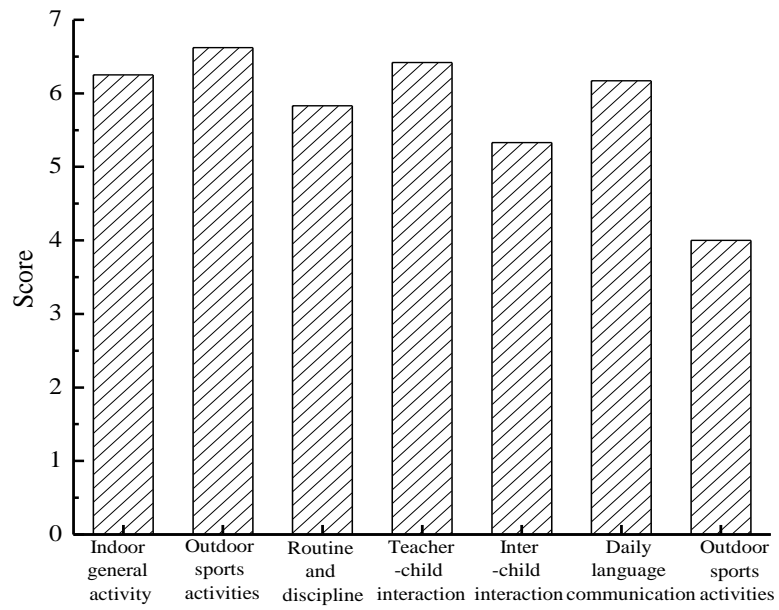

Figure 1. Mean of kindergarten interaction scores.

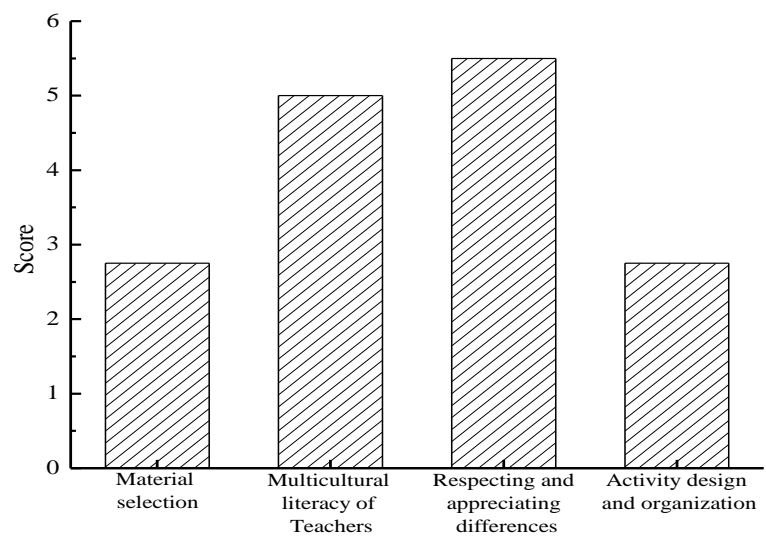

Figure 2. Mean of multi-culture and difference acceptance. 


\section{Action Process and Discussion of Kindergarten Multicultural Education Promotion through Game- based Teaching}

Researchers have found that children know more about traditional festivals at home and abroad. Traditional culture is an important cultural heritage of China with deep cultural connotations. The Dragon Boat Festival and the Spring Festival are traditional festivals in China, and Thanksgiving is a traditional festival in Western countries. Chinese and Western festivals can be taught to children through the most basic game. In the process, children's solidarity and cooperation can also be cultivated. Figure 3 is a game plan diagram for the Dragon Boat Festival, which includes wrapping zongzi, decorating dragon boats and group performance. The teacher guides children to cooperate in the corresponding group activities. Figure 4 is a game plan diagram for the Thanksgiving. Through the Thanksgiving activities, the children's collaboration ability and cultural literacy can be enhanced. Figure 5 is a game plan diagram for the Spring Festival. More festival-based activities will bring more traditional culture education on the children and thus greatly enhance their collaboration ability in the team.

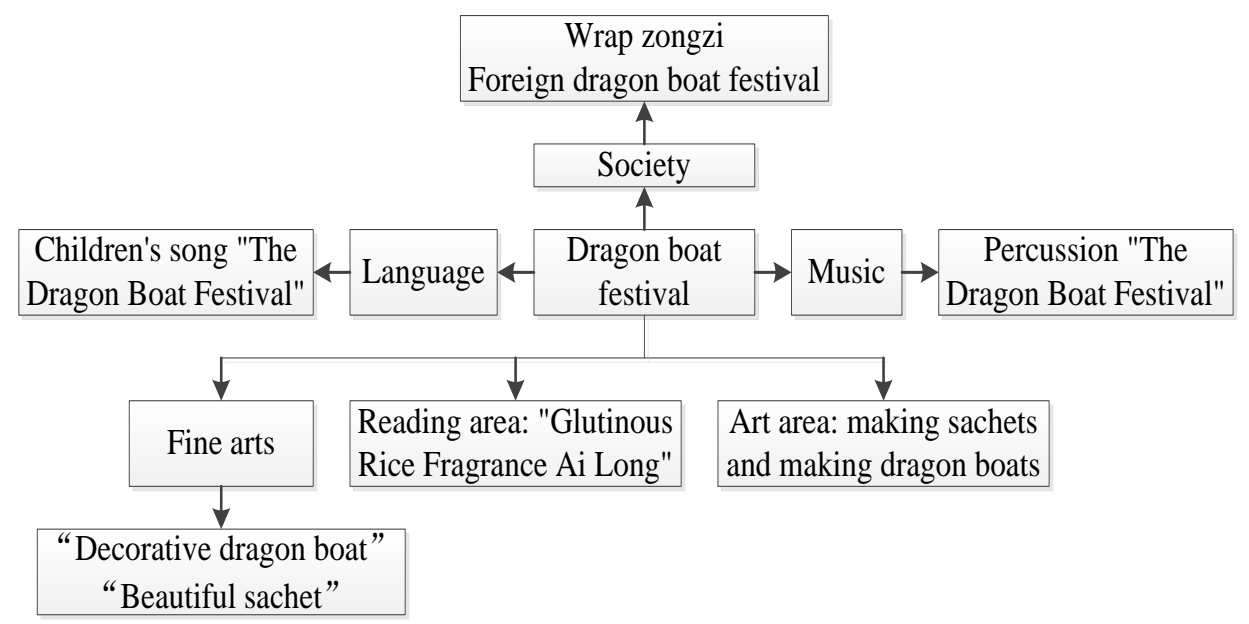

Figure 3. Dragon boat festival game plan diagram.

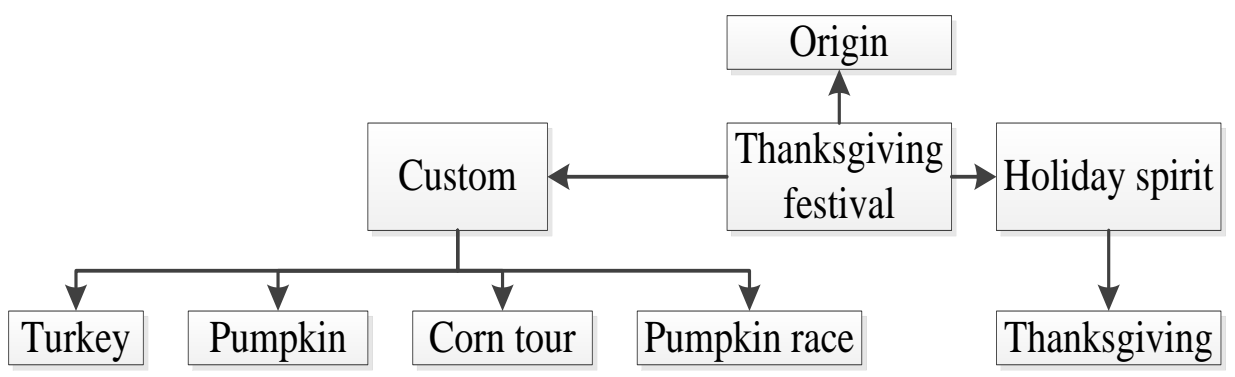

Figure 4. Thanksgiving game plan diagram. 


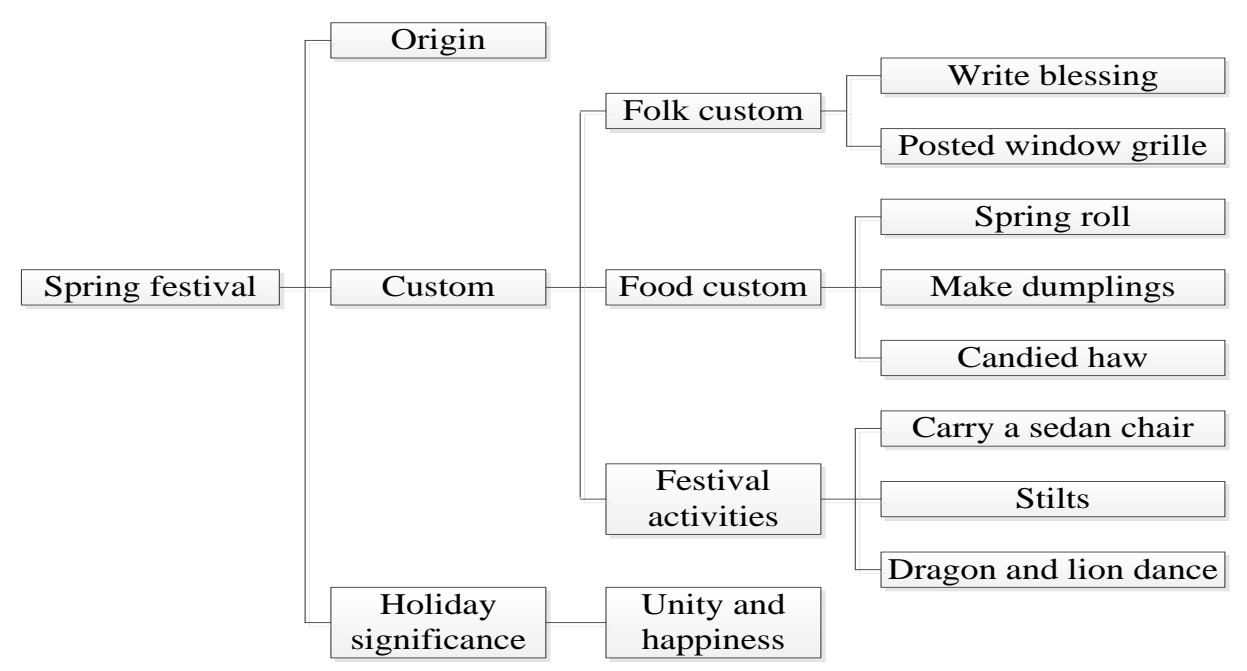

Figure 5. Spring festival game plan diagram.

\section{Case Study of Collaboration in Kindergarten Game-based Education}

\section{Teaching and Learning of Collaboration in Kindergarten Game-based Education}

The organization and implementation of kindergarten game-based education is a cyclical process. It is necessary to constantly adjust the teaching and learning in preschool game-based education to promote the comprehensive and coordinated development of children. Before the game, the teacher creates game scenes (which can be culture, entertainment, performances, etc.) and guides children to imagine and feel the game scene. A kindergarten in Guangdong Province often organizes outdoor games for education. Children and teachers collectively complete the overall planning and environment construction of the game venues, which greatly enhances the children's collaboration ability and fully exert their imagination, and thus maximizes children's learning and development interests and demands. Outdoor game-based education can promote children's environmental perception, increase team unity and cooperation in the game, and enhance selfconfidence and personal control, so as to promote the comprehensive development of children in the culture, entertainment and humanistic education.

In the preschool game-based education, teachers should try to materialize the educational goals of collaboration through environmental creation, and can guide children per needs through the process of "starting games-observing games - generating teaching cases". In this process, children will also actively build knowledge in the game-based education through "experience repetition - self-challenge - problem solving". 


\section{The Relationship between Kindergarten Game-based Education and Curriculum Contents and}

\section{Teachers' Professionalism}

The game-based education is embodied in the teaching case generated by teachers. The collaboration during the game and the experience sharing after the game are the values of the game-based education. In order to study the application of collaboration in kindergarten game-based education, it is necessary to understand the relationship between the kindergarten game-based education and curriculum contents and teachers' professionalism. In this paper, 84 kindergartens (all located in Guangdong Province) were surveyed. Figure 6 shows the frequency of teaching cases generated in different game behaviours. It can be seen that the percentage of teaching cases generated by game behaviours in construction is the largest, followed by sports, dress-up and sand-water games. Table 1 shows the frequency and percentage of different organizational forms of teaching generated. The immediate intervention sees the highest percentage, followed by sharing and communication, and preset teaching. Figure 7 shows the percentage of teachers' observation and analysis of game behaviour perspectives in individual cases. It can be seen that cognitive experience has the highest percentage in game behaviors, reaching $51.7 \%$, followed by problem solving, self-challenge and learning quality. Figure 8 shows the percentage of teacher-supported game behaviors in the generated teaching cases. From the perspective of teacher-supported games, the percentages of cognitive experience, learning quality and self-challenge are relatively high.

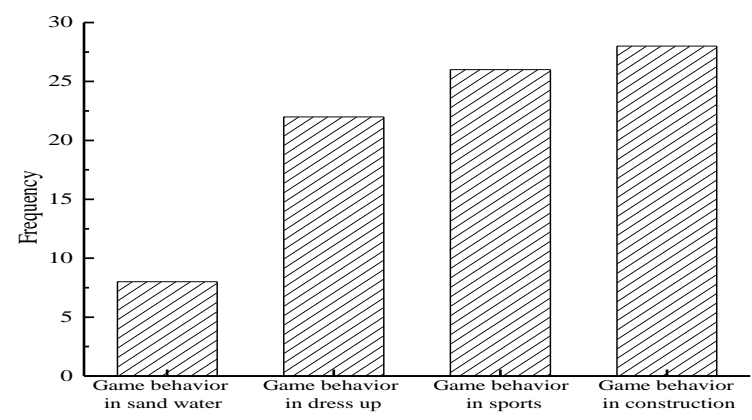

Figure 6. Frequency of teaching generated in different game behaviours.

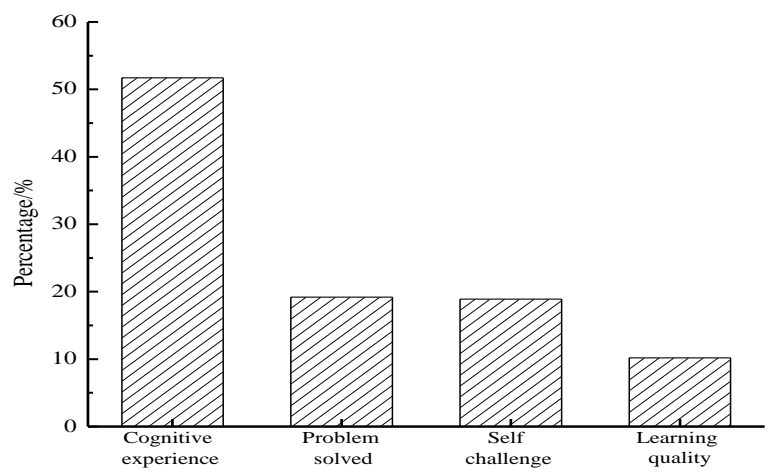

Figure 7. Percentage of teachers' observations and analysis of game behavioral perspectives in individual cases. 


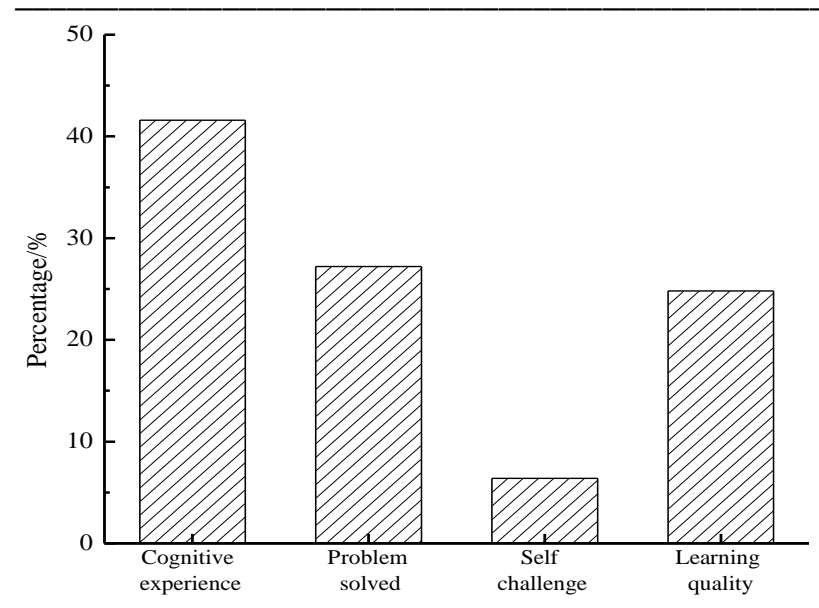

Figure 8. Percentage of teacher-supported game behavior perspectives in generated teaching cases.

Table 1

Frequency and Percentage of Different Organizational Forms of Teaching Generated

\begin{tabular}{lcccc}
\hline $\begin{array}{l}\text { Organizational } \\
\text { form }\end{array}$ & $\begin{array}{c}\text { Immediate } \\
\text { intervention }\end{array}$ & $\begin{array}{c}\text { Sharing and } \\
\text { communication }\end{array}$ & $\begin{array}{c}\text { Presuppositional } \\
\text { teaching }\end{array}$ & Total \\
\hline $\begin{array}{l}\text { Frequency } \\
\text { Percentage }\end{array}$ & 40 & 33 & 17 & 90 \\
\hline
\end{tabular}

\section{Conclusion}

This paper, under the background of kindergarten multicultural education, studied the application of collaboration in the kindergarten game-based education. The conclusions are detailed as follows:

(1) Guided games targets planned learning with children as the main body, while free games and direct teaching games are the two extremes of kindergarten game-based education that have little effect on the multicultural spread.

(2) Kindergartens, through Dragon Boat Festival, Thanksgiving Day and Spring Festival games, can enhance the multi-cultural education on children and greatly enhance children's collaboration ability in the team.

(3) Regarding the outdoor game-based education in kindergartens, the overall planning and environment construction of the game venue are completed by children and teachers, which greatly enhances the children's collaboration ability and fully play their imagination to maximize the children's interests and needs for learning and development. 


\section{References}

Barnett, J. E. H. (2015). Enhancing collaboration between occupational therapists and early childhood educators working with children on the autism spectrum. Early Childhood Education Journal, 43(6), 467-472. http://dx.doi. org/10.1007/s10643-015-0689-2

Cicconi, M. (2014). Vygotsky meets technology: a reinvention of collaboration in the early childhood mathematics classroom. Early Childhood Education Journal, 42(1), 57-65. http://dx.doi. org/10.1007/s10643-013-0582-9

Coughlin, C. (2015). The influence of student teachers on the perspectives of early childhood cooperating teachers regarding early reading instruction. Asia-Pacific Journal of Teacher Education, 43(3), 243-261. http://dx.doi. org/10.1080/1359866X.2014.934198

Eckhoff, A. (2011). Art experiments: introducing an artist-in-residence programme in early childhood education. Early Child Development \& Care, 181(3), 371-385.http://dx.doi. org/10.1080/03004430903388089

Green, N., Wolodko, B., Stewart, C., Edwards, H., Brooks, M., \& Littledyke, R. (2013). Collaborative selfstudy of online teaching in early childhood teacher education. International Journal for Academic Development, 18(2), 166-177. http://dx.doi. org/10.1080/1360144X.2012.677747

Lazzari, A. (2012). Reconceptualising professionalism in early childhood education: Insights from a study carried out in bologna. Early Years, 32(3), 252-265. http://dx.doi. org/10.1080/09575146.2011.651711

Lee, G. L. (2013). Re-emphasizing character education in early childhood programs: Korean children's experiences. Childhood Education, 89(5), 315-322. http://dx.doi. org/10.1080/00094056.2013.830907

O'Malley, D., Woods-Jaeger, B. A., \& Dowd, M. D. (2017). Building a collaboration between a children's hospital and an early childhood education and social services center. Current Problems in Pediatric \& Adolescent Health Care, 47(9), 222-228. http://dx.doi. org/10.1016/j.cppeds.2017.07.008

Silverman, K., Hong, S. B., \& Trepanierstreet, M. (2010). Collaboration of teacher education and child disability health care: transdisciplinary approach to inclusive practice for early childhood pre-service teachers. Early Childhood Education Journal, 37(6), 461-468. http://dx.doi. org/10.1007/s10643-010-0373-5

Yilmaz, R. M., \& Chb, J. (2016). Educational magic toys developed with augmented reality technology for early childhood education. Computers in Human Behavior, 54(C), 240-248. http://dx.doi. org/10.1016/j.chb.2015.07.040 